\title{
LA REPRESENTACIÓN ICÓNICA Y NARRATIVA DE LA MUJER EN EL CÓMIC JAPONÉS \\ MASCULINO: EL SHOUNEN MANGA Y EL HORROR MANGA
}

\author{
Juan A. García Pacheco \\ juana.garciap@estudiante.uam.es \\ Universidad Autónoma de Madrid
}

Francisco J. López Rodríguez

flopez9@us.es

Universidad de Sevilla

Recibido: 22-11-2011

Aceptado: 03-03-2012

\section{Resumen}

El cómic japonés (Manga) es un importante medio de comunicación en su país de origen y, gracias su progresiva expansión internacional, en muchos países occidentales. Gran parte de los estudios de género realizados sobre el cómic japonés se han centrado en las obras dirigidas a una audiencia femenina. El presente artículo analiza un área menos abordada como es la representación de la mujer en el cómic japonés masculino, la cual es estudiada a través de dos métodos de análisis (iconográfico y narrativo) en dos tipos de cómics bien definidos en sus características como son el cómic de acción y aventura para adolescentes masculinos (shounen manga) y el cómic de terror (horror manga) para el público adulto.

Palabras clave: Cómic japonés, mujer, personaje femenino, shounen manga, horror manga.

\begin{abstract}
Japanese comics (Manga) are an important mean of communication in their country and, because of their progressive international expansion, in many Western countries as well. Most of the gender studies performed on Japanese comics had focused on the works targeted at a female audience. This article studies the representation of women in Japanese male comics through iconographic and narrative analysis of two different types of comics: action comics for male teenage audiences (shounen manga) and horror comics for an adult public (horror manga).
\end{abstract}

Keywords: Japanese comics, woman, female character, shounen manga, horror manga. 


\section{Introducción. El cómic japonés como medio de comunicación}

La expansión, el consumo y la influencia de los cómics en Japón es tan importante que son varioslos académicos que consideran el manga ${ }^{1}$ un medio de comunicación de masas equiparable al cine o la televisión. José Andrés Santiago (2010: 17) declara rotundamente que "el manga es la manifestación cultural más importante en Japón” dada su omnipresencia en todas las facetas de la vida diaria y laboral, el volumen de negocio que representa y su capacidad de impregnar a otros medios como el cine, la televisión, la literatura, la publicidad o la educación. Jaqueline Berndt (1995: 28), pionera en el estudio del manga desde una perspectiva académica, también señala que "junto con la televisión, el video y los diferentes soportes de audio, el manga se ha convertido en uno de los más importantes medios de comunicación de masas en el Japón”. Mark MacWilliams (2008: 6), por su parte, aplica el concepto de "arte de masas" acuñado por el filósofo Noël Carroll para referirse al cómic y la animación en Japón. Según este autor, el arte de masas ha emergido recientemente en las sociedades urbanas, industriales y capitalistas y se caracteriza por su distribución mecánica y digital, gracias a la cual puede alcanzar inmensas audiencias.

En el caso del cómic japonés, observamos que también se trata de una industria cultural y artística tremendamente lucrativa que generó en el año 2011 un total de 271,71 billones de yenes (unos 3,533 billones de dólares, unos 2,650 billones de euros al cambio) durante el año fiscal del 2011. Dicha cifra fue generada por las ventas de más de 503 millones de cómics en Japón, algo inferior a la del año anterior por los efectos adversos del tsunami del 11 de marzo de $2011^{2}$. En el caso de España, resulta difícil ofrecer datos tan exactos referentes al mercado nacional por la inexistencia de ningún organismo que recopile y publique dichas cifras. Las propias editoriales que comercializan cómic japonés en España son algo reacias a ofrecer informaciones como tiradas o número de ventas, por lo que debemos atender a estimaciones aproximadas para hacernos una idea del volumen de negocio generado por el manga. Madrid y Martínez ofrecen datos relativos a la evolución de la publicación de cómics japoneses en España y muestran que existe una clara tendencia al auge, aunque recientemente ha disminuido el número de novedades publicadas debido a la crisis económica. Así, estos autores señala que en 2009 se publicaron en España 674 tomos de manga (frente a los 1.460 que aparecieron en el mercado francés) y que una de las series más exitosa, Naruto, ha vendido 1,5 millones de ejemplares en 10 años, lo cual arroja una cifra

\footnotetext{
${ }^{1}$ La palabra manga, utilizada actualmente para referirse al cómic producido por creadores japoneses, fue acuñada en 1814 por el artista Katsuhika Hakusai (1760-1849) aunque su uso no se extendería hasta comienzos del siglo XX, cuando el dibujante Rakuten Kitazawa (1876-1955) recuperara dicho vocablo para nombrar así a su obra (Moliné, 2002: 17).

${ }^{2}$ Datos obtenidos del ranking elaborado por la empresa Oricon, especializada en la elaboración de rankings de ventas de CDs de música, DVDs, videojuegos, cómics y otros productos de entretenimiento. Para más información: http://www.animenewsnetwork.com/news/2012-01-23/2011-comic-sales-totaled271.71-billion-yen-in-japan [28/01/2012].
} 
media aproximada de unos 34.000 ejemplares vendidos por cada tomo que compone la colección (2010: 53-56).

Como vemos, el cómic japonés no es únicamente un destacado medio de comunicación en su país de origen sino que en los últimos años ha cobrado una especial relevancia en países occidentales. Ello se debe a la progresiva expansión internacional de diversas manifestaciones de la cultura popular japonesa que tuvo lugar durante la década de los años 90 del pasado siglo, en la que también podemos ubicar la animación japonesa (conocida como anime), los videojuegos o ciertos géneros del cine japonés contemporáneo.

Así, ya sea a través de los tradicionales procedimientos comerciales para la distribución de productos culturales o a través de nuevas estrategias de participación propiciadas gracias al desarrollo de la tecnología digital y las redes de comunicación (López Rodríguez, 2011), el cómic japonés se ha convertido en un producto ampliamente consumido en países como España (Madrid y Martínez, 2010), Francia (Bouissou, 2006) o Estados Unidos (Goldberg, 2010). Por ello, ante la creciente distribución internacional del cómic japonés, la comunidad académica ha comenzado a interesarse por este medio de expresión desde diversas perspectivas. En la mayoría de los casos, la investigación sobre el manga procede del campo de los estudios culturales, la comunicación intercultural, la narrativa gráfica o audiovisual así como la recepción de las obras. Recientemente se han ido ampliando las líneas de análisis y han surgido trabajos que estudian el cómic nipón desde perspectivas históricas, temáticas o autoriales, por lo que se ha ido profundizando en sus características esenciales como medio de comunicación con una estética, un lenguaje, una taxonomía y una ideología propias.

\section{Estudios de género y cómic japonés}

La investigación sobre la mujer en el cómic japonés puede dividirse en tres grandes áreas de modo similar a las que encontramos en el estudio feminista del cine (Guarinos, 2008). Así, en primer lugar podemos establecer el estudio de la mujer como autora, creadora, guionista o dibujante de cómics. Esta línea de investigación es, hasta la fecha, la que menos ha avanzado tanto por la desidia de la comunidad científica como por la propia escasez de mujeres creadoras dentro de la industria. Uno de los escasos trabajos centrados en la mujer como autora de cómic japonés es el artículo de Ruh titulado "The Function of WomanAuthored Manga in Japanese Society", en el que analiza la representación de roles de género en tres cómics creados por mujeres (en concreto, CLAMP, Akimi Yoshida y Rumiko Takahashi). Ruh concluye que "the liminal space of manga provides an excellent fórum for the discussion of gender construction in Japanese society" (2001: online) pero destaca la necesidad de investigar más en profundidad este aspecto. De hecho, el propio trabajo de Ruh es limitado en tanto que aborda únicamente los primeros tomos de las obras analizadas (sin atender completamente a la evolución narrativa de los personajes), se centra en títulos 
pertenecientes al género shôjo (cómic especialmente dirigido al público femenino) y no tiene en cuenta la trayectoria completa de las creadoras abordadas. En este sentido, resulta necesario ahondar en el modo en que la mujer creadora se enfrenta a géneros tradicionalmente desarrollados por autores masculinos (como el cómic de acción y aventuras, el cómic deportivo o el cómic pornográfico). Del mismo modo, ciertas autoras de cómic que han obtenido gran éxito internacional, como Rumiko Takahashi, Hiromu Arakawa o el grupo CLAMP, o pioneras del cómic para jovencitas, como el grupo del año $24^{3}$, merecen ser estudiadas en profundidad.

La segunda perspectiva se centra en la mujer como consumidora de manga. Esta línea entronca a menudo con los fandom studies desarrollados recientemente en tanto que es muy frecuente la generación de comunidades de aficionados alrededor del cómic y otras manifestaciones de la cultura popular japonesa, lo cual conlleva la participación en actividades específicas como salones del manga, cosplay (disfrazarse de un personaje de cómic, animación, videojuego o cine e interpretarlo), creación o distribución de fansubs y scanlations, etc. En este sentido, encontramos un cierto interés en el estudio del cosplay, tal y como evidencian las publicaciones existentes dedicadas al fenómeno (Gómez Aragón, 2011; Nagaike y Yoshi, 2011; Gallego Andrada y Gándara Martín, 2010) así como en los fans occidentales de productos específicos de la cultura popular japonesa (Napier, 2007). En general, las dos vertientes más exploradas de esta perspectiva son el análisis de la recepción de manga por parte de una audiencia extranjera, es decir, como comunicación transcultural (Brienza, 2009; Natsume, 2001); y la figura de la receptora que se convierte en creadora, pues son muchas las fans del cómic y la animación japonesa que elaboran sus propios relatos o cómics sobre sus personajes favoritos (Thorn, 2004; McLelland, 2001; Kinsella, 2000). Dado que la consumidora se convierte en creadora, el estudio de estos mensajes debe atender a aspectos propios de la primera (la mujer como creadora) y esta segunda línea de investigación. No obstante, resulta necesario avanzar más en los estudios sobre el modo en que la lectora recibe, interpreta y reacciona ante los contenidos del cómic japonés.

Por último, la tercera área de los estudios de género sobre cómic japonés es, con diferencia, la más numerosa y desarrollada aunque, como veremos, todavía quedan huecos que cubrir. Se trata del análisis de la representación de la mujer en el manga, aspecto sobre el cual se han elaborado diversas publicaciones. En este sentido, debemos remarcar que el estudio de la mujer está directamente vinculado con el del género taxonómico de las obras. Dado que la configuración de la industria japonesa del cómic está fuertemente estructurada en función de las características del público objetivo al que se dirige, principalmente la edad y el género, es posible encontrar obras orientadas a diferentes segmentos de la audiencia. En palabras de Paul Gravett, "the Japanese have liberated the medium's language from confining

\footnotetext{
${ }^{3}$ La denominación "el grupo del año 24" hace referencia al año de nacimiento de muchas de estas creadoras: el año 24 de era Shôwa, es decir, 1949. El grupo incluye autoras de cómic como Keiko Takemiya, Machiko Satonaka, Moto Hagio, Ryôko Yamagishi y Yukio Ôshima (Ito, 2008: 39).
} 
formats and genres of the daily newspaper strip or 32 page American comic book, and expanded its potential to embrace long, free form narrative on almost every subject, for both sexes and almost every age" (2004: 10-13). Así pues, hasta el momento, los principales trabajos académicos que han abordado la representación de la mujer en el manga se han centrado principalmente en el shôjo y el josei ${ }^{4}$, es decir, aquellos cómics dirigidos específicamente a audiencias femeninas.

Dado que la mayoría de obras incluidas dentro de estas categorías son creadas por autoras y consumidas por una audiencia femenina, esos sectores de la producción cultural japonesa suponen un campo bien limitado para el estudio de la construcción de la feminidad a través de las características físicas, emocionales y narrativas de las protagonistas así como del tratamiento y la temática de dichas obras. Así pues, en esta línea, podemos destacar trabajos como el de Kanako Shiokawa, que analiza la estética kawaii en los cómics para chicas y concluye que "the Japanesevision of the 'cute' female provides a strategic guideline for a girl child to benefit in a grossly imperfect worlddominated by grown-up boys, but it also deludes her into believing the relative importance of being 'cute'“" (1999: 121); el de Takahashi Mizuki (2008), que analiza la construcción iconográfica de la mujer en el cómic para jovencitas a través de los principales rasgos estéticos; o el de Deborah Shamoon, que presta atención a la plasmación de relatos de temática homosexual y considera que estas obras "provide a space for women artists to explore the tensions and contradictions of shôjo identity (2008: 153).

No obstante, pese a que el estudio del shôjo y el josei resulte imprescindible en la investigación sobre género en el manga, consideramos necesario ampliar el campo de análisis hacia otros tipos de cómics para conseguir una perspectiva más global en lo que respecta a la representación de la mujer en el cómic japonés. Ruh (2001) expuso la necesidad de llevar los estudios de género al cómic para público masculino y ése es precisamente el objetivo de este artículo: estudiar cómo se representa el personaje femenino a nivel icónico y narrativo en cómics orientados a audiencias masculinas.

\section{Objetivos y metodología de análisis}

Los objetivos que persigue el presente artículo pueden ser resumidos en dos puntos principales. Por un lado, en el epígrafe anterior se ha ofrecido una perspectiva general de las

\footnotetext{
${ }^{4}$ El cómic japonés orientado a audiencias femeninas puede ser dividido en dos grandes grupos. Por un lado encontramos obras dirigidas a chicas adolescentes de entre 12 y 20 años, las cuales son conocidas como shôjo manga. Por el otro lado, también existen cómics para mujeres adultas que han superado ya los 21 años. Se trata del josei manga. Pese a compartir temáticas y estilos gráficos similares, el joseipresenta un tratamiento más realista y directo de historias así como planteamientos más maduros. No obstante, la barrera entre ambos tipos de obras para audiencias femeninas es muy tenue, por lo que son frecuentes las obras que difícilmente pueden ser catalogadas dentro de una u otra categoría.
} 
investigaciones en materia de género realizadas en relación con el cómic japonés para identificar aquellas áreas o líneas de estudio que necesitan ser abordadas. De este modo, a través de la exposición de las principales aportaciones teóricas realizadas en este campo, se pretende fomentar la investigación en España sobre género y manifestaciones de la cultura popular japonesa que cada vez tienen mayor presencia en nuestro país, como el cómic, la animación o el videojuego.

El segundo objetivo consiste en analizar la representación icónica y narrativa del personaje femenino en el cómic japonés orientado a audiencias masculinas. En concreto, nos centraremos en dos tipos de cómics, el cómic de aventuras para adolescentes y el cómic de terror, a través del análisis en profundidad de una serie de títulos publicados en España. En el caso de los cómics de aventuras para jóvenes (conocidos como shounen manga), nos basaremos en nuestra investigación previa (López Rodríguez y García Pacheco, 2011) sobre ocho cómics concretos ${ }^{5}$ de este género para discutir aquí las características esenciales del personaje femenino. Respecto al cómic de terror japonés (horror manga), las escasez de obras de este tipo publicadas en España reducen considerablemente las posibilidades de realizar un estudio extensivo. En su defecto, hemos optado por el estudio en profundidad de un cómic de terror paradigmático por su éxito en Japón, Tomie (Junji Ito, 1990, 1995 y 2000), el cual fue editado en España en $2006^{6}$.

Dado que cada uno de estos géneros está orientado a un segmento de la audiencia con intereses diferentes, pretendemos realizar un análisis comparativo de la mujer en términos gráficos y narrativos. En este sentido, resulta necesario especificar que nuestro enfoque combina dos metodologías de análisis diferenciadas: el estudio de la construcción iconográfica y narrativa del personaje. De este modo, a través del contraste entre estos dos tipos de representación de lo femenino, se pretende comprender mejor cómo se construye y se utiliza a la mujer en el cómic japonés consumido por hombres. A continuación se detalla el marco de referencia utilizado para desarrollar estos análisis.

Tal y como señala Muro, en cómic "la figura icónica del cuerpo puede cumplir la función que el nombre propio desempeña en la narrativa, como núcleo sobre el que se efectúa la referencia que constituye el personaje" (2004: 199-200). En este sentido, la apariencia física del personaje supone una descripción básica puesto que simplemente con observar sus características iconográficas podemos llegar a concebir una cierta idea de sus funciones narrativas, su posición en el relato y su construcción como persona. En lo referente a la construcción iconográfica de la mujer debemos tener en cuenta, tal y como señala Eisner (1990: 102), que "el cuerpo humano, la estilización de sus formas, la codificación de su gesticulación emocional y sus expresivas posturas, todo ello está almacenado y registrado en

\footnotetext{
${ }^{5}$ Dragon Ball (Akira Toriyama, 1986-1995), Naruto (Masashi Kishimoto, 1999-actualidad), Inu-Yasha (Rumiko Takahashi, 1996-2008), Death Note (Tsugumi Oba y TakeshiObata, 2003-2006), Ruroni Kenshin (Nobuhiro Watsuki, 1994-1999), Love Hina (Ken Akamatsu, 1998-2001), Slam Dunk (Takehiko Inoue, 1990-1996), y The Prince of Tennis (Takeshi Konomi, 1999-2008).

${ }^{6}$ La editorial La Cúpula editó dos tomos del cómic pero no el tercero, el cual está disponible en USA.
} 
la memoria, formando un vocabulario no verbal de gestualidad". Este inventario de cuerpos, gestos y posturas es la base inicial desde la cual los creadores de cómics comienzan a construir sus personajes gráficamente, pues toman como referentes a personas reales, personajes previos o rasgos concretos para elaborar a los personajes de sus narraciones.

Steven y Danner sugieren que detrás de cada personaje subyacen diversos paradigmas centrales o arquetipos que se remontan a los primeros mitos y leyendas, los cuales se combinan entre sí y evolucionan hasta conformar la amplia galería de personajes que podemos encontrar en cada obra (Withrow y Danner, 2007: 22). En el caso del manga, la construcción iconográfica de los personajes es una herramienta esencial que se nutre de numerosos estereotipos y arquetipos previamente establecidos por obras de éxito, por la sociedad o incluso por producciones de otros medios expresivos.

En términos generales, los personajes arquetípicos gráficamente o estereotipados suelen apreciarse como poco trabajados. Así, Varillas señala que "casi siempre que recurrimos a un repertorio de convenciones iconográficas para modelar a un personaje, estamos limitando la especificidad de ese modelo, creando por consiguiente, un estereotipo, un personaje plano" (Varillas, 2009: 44). No obstante, la utilización de estos personajes "tipo" proporciona una interesante economía narrativa al permitir caracterizar con tan sólo unos rasgos la apariencia (y, probablemente, la personalidad) del personaje en cuestión. Así, los criterios para estudiar la construcción icónica del personaje femenino han sido principalmente el cuerpo, la proporción anatómica, la longitud, la forma y el color del cabello, el peinado, el tamaño, la forma y el color de los ojos, la expresión del rostro, el vestuario y el uso de algún tipo de complemento. También se han tenido en cuenta las posiciones y posturas habituales que mantienen los personajes, pues a través de ellas se transmite una cierta impresión de su personalidad y su carácter.

En cuanto al análisis del personaje como construcción narrativa, en su estudio pionero sobre la morfología del cuento ruso, que serviría para construir las bases de la posterior teoría narratológica, Propp (1928: 32) define las funciones narrativas como "la acción de un personaje, definida desde el punto de vista de su significado en el desarrollo de la intriga". Estas acciones son elementos constantes que aparecen en los relatos independientemente de los personajes que las lleven a cabo o cómo se realicen. Propp delimitó las funciones constitutivas de los cuentos populares rusos para establecer su estructura interna y demostró que estas funciones eran limitadas, pudiendo establecerse un catálogo de estas acciones básicas. Del mismo modo Barthes, en su "Introducción al análisis estructural de los relatos", tras examinar diversas aportaciones teóricas sobre el estudio del personaje en las narraciones, concluye que todas ellas tienen en común el hecho de definir al personaje por su participación en una serie de esferas limitadas, típicas y clasificables. Es decir, el nivel de las acciones del personaje debe ser entendido "en el sentido de las grandes articulaciones de la praxis (desear, comunicar, luchar)" (Barthes, 1966: 87). 
Dado que la construcción narrativa del cómic japonés en sus diferentes géneros puede ser considerada como una tipología textual relativamente cerrada, nuestra intención es examinar cuáles son las funciones narrativas desempeñadas por los personajes femeninos a partir de las acciones que realizan dentro de la estructura del relato. Así pues, en este caso, nos centraremos en el estudio del personaje como rol.

A diferencia del personaje como persona (que atiende a sus particularidades físicas, psíquicas, emocionales y sociales) y del personaje como actante (que se correspondería con la posición que ocupa en la estructura profunda del relato), entender el personaje como rol implica que "ya no nos encontramos frente a un personaje como individuo único, irreductible, sino frente a un personaje como elemento codificado" (Casetti y Di Chio, 1990: 179) que puede ser dividido en distintos "tipos" de personajes. La evolución histórica de los medios de expresión humanos ha hecho que estos tipos deriven en estereotipos, es decir, patrones de personajes reconocibles por su aspecto o sus acciones de modo que el espectador pueda identificarlos fácilmente en aras de una mayor economía narrativa. Muchos de estos patrones aparecen en otros discursos como el publicitario, el literario o el informativo, por lo que se hace necesario proceder al estudio de los personajes femeninos del cómic japonés para establecer qué tipos aparecen y qué funciones realizan.

\section{Resultados}

\subsection{La mujer en el cómic para adolescentes: el shounen manga}

El cómic japonés dirigido a audiencias masculinas adolescentes comprendidas entre los 12 y los 20 años es el sector más exitoso tanto dentro como fuera de Japón ${ }^{7}$. Las obras dirigidas a esta audiencia, que suelen encuadrarse dentro del shounen manga (cómics para chicos), presentan una cierta variedad de historias y temáticas pero, en general, suelen componerse de acción, aventura y humor. Se trata de un género muy formulaico y altamente codificado en sus apartados gráficos y narrativos, por lo que podemos establecer las características principales que definen a la mayoría de obras pertenecientes a este género. En primer lugar, es muy habitual la presencia de protagonistas masculinos, normalmente con la misma edad del público al que se dirige la obra, entre los 12 y los 20 años. Estos personajes, que muchas veces carecen de familia u hogar, suelen ser diferentes a los demás en ciertos aspectos y destacan por sus habilidades, ya sean innatas o adquiridas.

En segundo lugar, podemos observar personajes secundarios (aliados y oponentes) altamente estereotipados que propician una economía narrativa basada en la repetición de

\footnotetext{
${ }^{7}$ Las obras más representativas de este género como Dragon Ball (Akira Toriyama, 1986-1995), Naruto (Masashi Kishimoto, 1999-actualidad) o Slam Dunk (Takehiko Inoue, 1990-1996) han vendido millones de ejemplares y alcanzado récords de ventas en diversos países.
} 
patrones que han funcionado en obras previas. En tercer lugar, es muy común hallar una estructura argumental construida generalmente a través de tramas episódicas autoconclusivas de diferentes duraciones (desde un capítulo hasta varios tomos en las sagas más extensas) y basadas parcialmente en el viaje del héroe ${ }^{8}$.

A la hora de analizar la representación de la mujer en este tipo de obras, haremos referencia a una investigación previa llevada a cabo recientemente (López Rodríguez y García Pacheco, 2011). Dicho estudio se basó en una muestra de ocho cómics japoneses dirigidos a jóvenes adolescentes masculinos ${ }^{9}$, los cuales fueron escogidos a partir de los siguientes criterios: cómics editados en España, cómics que contaran con una adaptación a la animación japonesa y cómics que no superaran los veinticinco años de antigüedad. La muestra también atendió a la diversidad interna del género shounen manga, donde es posible establecer ciertos subtipos.

En concreto, entre las series analizadas, se incluyeron dos títulos de temática deportiva (pertenecientes al subgénero shounen conocido como spokon, en el que los personajes se dedican a la práctica de algún deporte) y un harem manga (cómic japonés en el que un personaje masculino debe convivir o tratar con multitud de chicas enamoradas de él). Tras el análisis de dichas obras se obtuvo un total de $42^{10}$ personajes femeninos que fueron estudiados sistemáticamente a través de una ficha de análisis de personajes.

Los resultados de los análisis se usaron como base para elaborar una tipología del personaje femenino en función de su aspecto iconográfico y su rol narrativo, además de ofrecer información sobre la edad, la profesión y la relevancia narrativa de la mujer en el cómic japonés para adolescentes. Así, casi la mitad de los personajes analizados tenía una edad comprendida entre los 14 y los 20 años de edad (el mismo tramo que el sector demográfico al que se dirigen los cómics) mientras que apenas aparecían mujeres niñas o ancianas. En lo referente a la profesión, este factor viene condicionado irremediablemente por la edad del personaje. Dado que la mayoría de los personajes femeninos son jóvenes adolescentes, la ocupación de estudiante es la más numerosa y era desempeñada por 12 de los 42 personajes analizados. Por último, el estudio reveló que el personaje femenino en el shounen mangaes eminentemente protagónico (mantiene el status quo del mundo

\footnotetext{
${ }^{8}$ Drummond-Mathews argumenta que la narrativa del shounen manga sigue el esquema del viaje del héroe expuesto por Joseph Campbell en El héroe de las mil caras, el cual consiste en un ciclo de etapas sucesivas: la llamada a la aventura, el rechazo a la llamada, el cruce de la barrera, la iniciación y el retorno (2010: 70-71). Aunque el modelo propuesto puede aplicarse a la macroestructura general de muchos argumentos de obras del género shounen, la larga duración de ciertas narrativas, la mezcla de tramas seriadas y episódicas así como determinadas convenciones genéricas hacen que sea posible encontrar variaciones del esquema propuesto por Drummond-Mathews.

${ }^{9}$ Ver nota 5.

${ }^{10}$ Los personajes Bulma y Chichi de la serie Dragon Ball aparecen contabilizados doblemente puesto que la extensión de la obra en la que participan hace que sean representadas como jovencitas y, más adelante, como mujeres maduras, cubriendo así dos tipos de personaje cada una de ellas.
} 
representado) y secundario (en escasísimas ocasiones se erige como el motor que hace avanzar el relato).

En lo referente a su diseño visual, la mayoría de los personajes femeninos son jóvenes y muy atractivos de modo que atributos como la fealdad, la gordura y los rasgos físicos desagradables tan sólo aparecen en las ancianas.Así pues, es posible establecer tres grados de atractivo en los personajes femeninos adolescentes y adultos: neutro (no son personajes feos pero tampoco especialmente hermosos), atractivos (personajes femeninos bellos, con curvas y una figura esbelta) y sexies (personajes femeninos hermosos con curvas destacadas que son realzadas por un vestuario provocativo). En este sentido, el pecho desmesurado es un rasgo recurrente en multitud de personajes femeninos. Puede aparecer tanto en personajes sexies como en otros más tímidos o despistados, por lo que viene a ser un rasgo general que aparece sobre todo en mujeres jóvenes, adultas y ancianas. Es necesario señalar que los personajes femeninos sexies tienden a ocupar el rol de antagonistas de los personajes masculinos, en contraposición a los personajes femeninos protagonistas más castos, puros y virginales. Así pues, es frecuente encontrar una relación directa entre la construcción iconográfica del personaje y su función en el relato.

En este sentido, podemos destacar que los personajes femeninos de ojos grandes y redondeados son más buenos, amables y positivos que aquellos personajes con los ojos pequeños y afilados; que las rubias suelen ser más activas, violentas, agresivas, polémicas y luchadoras que los personajes cuyo cabello es de otro color; y que el cabello moreno u oscuro es habitual en chicas tímidas, tranquilas o de belleza tradicional japonesa. Del mismo modo, encontramos varios arquetipos gráficos basados en el uso de un determinado vestuario, como es el caso de la colegiala, la sacerdotisa y la deportista, donde un atuendo específico sirve para comunicar visualmente la ocupación del personaje así como ciertos rasgos de su carácter, además de contener un cierto matiz fetichista.

En cuanto a su construcción narrativa, las funciones del personaje femenino surgen en directa relación con el personaje masculino y pueden dividirse según la acción básica que sustenta el vínculo entre ambos personajes: amar, ayudar y sufrir. El análisis demostró que el número de personajes femeninos que aman (24) es mayor que los que son amados (12), por lo que resulta evidente la sentimentalización de la mujer. Otros roles vinculados a la esfera del amor pero entendido éste no como amor romántico sino familiar serían los de la "madre" y la "abuela". En estos casos, su insignificante número demuestra que el amor sensual tiene mucha más importancia que otros tipos de sentimientos amorosos.

Los personajes femeninos que encontramos en torno a la acción de "ayudar" son más variados en acciones y en número. Aquí podemos incluir a las aliadas guerreras, a las sanadoras, a las consejeras y a las animadoras. Todas ellas se caracterizan por su posición secundaria respecto al personaje masculino y cómo, en cierto modo, contribuyen a complementarlo. Así pues, estos personajes demuestran que el héroe masculino no es absolutamente autosuficiente sino que necesita de la ayuda y el auxilio de otros personajes. En este sentido, es necesario mencionar la escasa relevancia que presenta la mujer guerrera, 
mucho más débil que el personaje masculino, de modo que se transmite la idea de que la mujer está mejor preparada para acometer funciones relacionadas con el consejo, el apoyo y la curación. Sin duda, se repiten arquetipos de lo femenino muy tradicionales y arcaicos.

Del mismo modo, el personaje femenino también es frecuentemente ayudado por el masculino en la forma del rescate o la liberación.Por último,los roles femeninos relacionados con la acción de "sufrir" pueden dividirse en dos: aquellos personajes que hacen sufrir a los demás (las enemigas) y los personajes que sufren (las víctimas, las atormentadas, las sometidas). En general, la mujer no suele ocupar a menudo el rol de enemiga y cuando lo hace nunca es la malvada principal, sino que sirve como apoyo dentro del grupo antagonista. Es más habitual encontrarla como personaje sufridor, como ser que necesita ayuda y protección por parte del protagonista masculino, de modo que se refuerza la imagen de la mujer como ser pasivo, sentimentalizado y que, en muchos casos, ella misma causa su propia perdición al seguir los designios de su corazón.

\subsection{La mujer en el cómic de terror: el horror manga}

Varios estudios académicos del género del terror desde un punto de vista feminista utilizan un marco de referencia basado en los conceptos de la teoría psicoanalítica. Así, en el conocido ensayo de Laura Mulvey (1975) se utiliza el temor a la castración y el fetichismo visual de Lacan para estudiar la representación de la mujer en la gran pantalla. Según esta autora, las mujeres son representadas de forma exhibicionista como objetos sexuales para los protagonistas de las películas y los espectadores. Pero la observación de la mujer plantea un gran problema puesto que, desde un punto de vista psicoanalítico, ella representa la falta del pene, la amenaza de la castración y la diferencia sexual. Por su parte, Barbara Creed (1993) utiliza el trabajo de la psicoanalista francesa Julia Kristeva para estudiar el horror en el cine. Kristeva (1982) localiza las fuentes del horror no en el complejo de castración sino en un estado pre-edípico del niño en el que surge una ambivalencia hacia la madre en tanto que el sujeto lucha por crear su propia identidad.

La madre se presenta como algo terrorífico en el sentido de que es una entidad envolvente, primitiva e impura. Creed explica que el terror utiliza la feminidad monstruosa a partir de la mostración de lo abyecto (cadáveres, fluidos corporales), la ruptura de los límites que simbolizan el status quo y una figura maternal terrible. Aunque estas aproximaciones hayan propiciado lecturas de obras de terror muy fructíferas, Freeland (1996) propone superar los conceptos extraídos del psicoanálisis para centrarnos en la propia construcción de las obras y observar el modo en que se representa el género. Así pues, nuestra aproximación al cómic de terror japonés se inscribe en esta línea que, básicamente, entronca con nuestra metodología de análisis.

En términos generales, la categoría del horror en el cómic japonés es bastante amplia y se nutre de multitud de referentes e influencias, por lo que nos encontramos ante una de las 
ramificaciones del manga más ricas y heterogéneas. Estas obras no sólo se basan en el propio folklore japonés, repleto de leyendas y mitos sobre fantasmas, demonios, duendes y demás criaturas sobrenaturales, sino que han absorbido numerosas referencias procedentes de la literatura, la religión y la mitología occidental así como de otros medios de expresión, principalmente el cine (Bryce y Davis, 2010: 38).

El terror surge como contenido temático en el cómic japonés hacia finales de los años cincuenta, con la irrupción del gekiga manga ${ }^{11}$ y sus historias plagadas de relatos truculentos en torno a misterios y crímenes. Shigeru Mizuki y Yoshiharu Tsuge son considerados como los primeros creadores en trabajar este género de forma continuada, aunque es posible señalar ciertas obras inspiradas en lo sobrenatural realizadas por Osamu Tezuka, como Vampiros (1966-67). Y, tal como señala Alfons Moliné, “desde mediados de los 60, con la aparición de las primeras publicaciones de manga específicamente para adultos, aparecen los primeros creadores especializados en el manga de terror puro, no apto para menores" (2003: 241). Entre estos autores debemos destacar a Hideshi Hino, Suehiro Maruo y Kazuo Umezu, cada uno de ellos con un estilo bien definido que dejaría su impronta en las sucesivas generaciones. Durante los años noventa, y coincidiendo con la revitalización del horror en el medio cinematográfico, se produce un auténtico boom del manga de terror con la aparición de publicaciones especializadas íntegramente en este género, como Halloween, y la llegada de nuevos autores (Moliné, 2003: 243). Entre esta nueva ola podemos destacar a la figura de Junji Ito cuya obra Tomie analizaremos en este epígrafe.

Tomie fue el primer gran éxito de Ito y ha sido editado en diversos países occidentales como Estados Unidos, Francia o España. Este cómic se compone de tres volúmenes que fueron publicados en los años 1990, 1995 y 2000 en Japón y cuyos capítulos fueron serializados en las revistas Monthly Halloween y Nemuki. Dicha obra presenta distintas historias independientes vinculadas entre sí por la presencia de Tomie, una joven tan bella y atractiva que todos los hombres que entran en contacto con ella terminan enamorándose hasta perder la razón y, en un ataque de celos, suelen asesinarla violentamente. Pero Tomie es inmortal y tiene la capacidad de multiplicar su cuerpo, por lo que siempre vuelve a la vida para desesperación de sus asesinos. La popularidad de este cómic no sólo es evidente en su distribución internacional sino en su trasvase al medio cinematográfico en tanto que, hasta la fecha, se han realizado ocho películas ${ }^{12}$ basadas en este título. Así pues, dada la relevancia de este personaje, analizaremos en términos iconográficos y narrativos la representación de Tomie como arquetipo de mujer monstruosa en el cómic de terror japonés.

\footnotetext{
${ }^{11}$ En 1957, el creador de manga Yoshihiro Tatsumi acuñó el término gekiga (que literalmente significa "dibujos dramáticos") para referirse a los nuevos cómics que presentaban contenidos más maduros, un mayor grado de realismo gráfico y temas relacionados con la sociedad y la política (Kinsella, 2000: 25).

${ }_{12}$ Tomie (Ataru Oikawa, 1999), Tomie: Another Face (Toshiro Inomata, 1999), Tomie: Replay (Tomijiro Mituishi, 2001), Tomie: Rebirth (Takashi Shimizu, 2001), Tomie: Forbidden Fruit (Shun Nakahara, 2002), Tomie: Beginning (Ataru Oikawa, 2005), Tomie: Revenge (Ataru Oikawa, 2005), Tomie vs Tomie (Tomohiro Kubo, 2007) y Tomie Unlimited (Noboru Iguchi, 2011).
} 
En su caracterización visual, Tomie aparece generalmente representada como una mujer joven cuya edad se sitúa entre los 18 y los 24 años, aunque también ha aparecido en forma de niña en ciertos episodios. Las características físicas de Tomie son siempre las mismas: es muy hermosa, delgada, pálida, con el cabello largo y oscuro. Casi siempre lleva la melena suelta de modo que caiga sobre sus hombros y viste ropa femenina, como faldas, vestidos y uniformes escolares.El rasgo característico que identifica al personaje es un pequeño lunar bajo su ojo izquierdo, el cual termina por aparecer en los cuerpos de las mujeres que son poseídas por Tomie.

Este personaje tiene una personalidad retorcida y manipuladora pues no duda en utilizar sus encantos para conseguir que los hombres satisfagan sus deseos. Cuando intenta seducir a un hombre, despliega una imagen inicial de dulzura y timidez que, unida a su belleza física, termina por conquistarlos. Una vez que tiene a los hombres bajo su control muestra una personalidad autoritaria, fría, calculadora y vengativa. Tomie pasa de ser una chica sumisa y dócil a convertirse en una verdadera harpía capaz de insultar y amenazar a cualquiera que se interponga en su camino. Aquellos hombres que han caído bajo el influjo de Tomie intentan hacer todo lo que ella les pide y se desviven por satisfacer sus apetencias, que van desde comprar ropas caras a cometer asesinatos. No obstante, estos hombres terminan enloqueciendo y asesinando a Tomie en un intento por "poseerla" definitivamente.

En cuanto a la dimensión de Tomie como rol dentro del relato, observamos claramente que se trata de un personaje que aúna en sí mismo la pasividad y la actividad. Tomie es un personaje pasivo en tanto que sufre en numerosas ocasiones la acción de sus enamorados, es decir, los asesinatos. Pero lejos de mantener esa pasividad y limitarse a morir, ella vuelve a la vida una vez tras otra. El regreso de Tomie es una muestra de su naturaleza activa pues ella es la fuente primordial de la acción y quien origina los acontecimientos de las tramas. En cierto modo, la pasividad de Tomie es simulada puesto que es ella misma quien provoca sus muertes. Ella enloquece a los hombres con su belleza, los utiliza, los humilla en algunas ocasiones, para luego seducir a otros hombres. Resulta extraño que un personaje tan activo se deje matar (Tomie nunca huye de sus asesinos ni se defiende ni responde a sus golpes) ya que lo cierto es que la muerte no es más que una etapa vital para ella, nada definitivo, por lo que en la pasividad con la que encara sus asesinatos podemos ver simplemente la aceptación y la resignación ante lo inevitable. El rol eminentemente activo de Tomie se manifiesta asimismo en su naturaleza autónoma, influenciadora y modificadora. En última instancia, Tomie es un personaje antagonista que atenta contra el mundo de los protagonistas, amenazando no sólo su raciocinio y su libertad para actuar por sí mismos sino también su identidad y sus vidas.

En última instancia, Tomie puede ser leída como una mujer monstruosa tanto por su actitud y sus acciones como por sus capacidades sobrenaturales (regeneración, posibilidad de resucitar, posesión de los cuerpos de otras mujeres). Según Carroll (1990), una de las características de los monstruos es su violación de lo que psicológica, física, o socialmente se considera aceptable. Del mismo modo, Kristeva también considera lo abyecto, lo horroroso, 
como aquello que no respeta fronteras, posiciones, o reglas (1982: 4). Es decir, lo ambiguo, lo compuesto, lo mentiroso, lo hipócrita son manifestaciones de la monstruosidad en tanto que ocultan su esencia primigenia. En este sentido, Tomie, con su rechazo absoluto a toda moral, a las relaciones de género tradicionales y a la autoridad masculina, surge como símbolo del individualismo y de una feminidad que se construye, al menos ficcionalmente, como amenazante y peligrosa.

\section{Conclusiones}

Como hemos podido comprobar, la representación de la mujer en el cómic japonés dirigido a un público principalmente masculino está fuertemente influenciada por el género taxonómico de la obra en cuestión. Si en los cómics de acción y aventuras para adolescentes la mujer desempeña posiciones secundarias subordinadas al protagonista masculino, como ayudante y sujeto amoroso principalmente, y con una representación icónica basada en el atractivo físico, la juventud y la belleza, el cómic de terror dirigido a un público más adulto utiliza habitualmente a la mujer como entidad amenazante, terrorífica, sobrenatural y peligrosa. En el caso analizado, Tomie, la mujer es un objeto que perturba la vida de los protagonistas a través de la seducción, la ruptura de la identidad y la resistencia a la tradición patriarcal. Resulta evidente, por tanto, el carácter contradictorio y opuesto de estas dos construcciones de lo femenino. Así pues, a la hora de alcanzar las conclusiones, debemos plantearnos una cuestión esencial en el estudio de la representación de la mujer en el cómic japonés: ¿hasta qué punto podemos considerar la visión que se ofrece del personaje femenino en este medio de comunicación como representativa de la situación sociocultural de la mujer japonesa?

Por un lado, determinados autores consideran que el cómic, al igual que otros medios de comunicación, proporciona un reflejo (aunque se trate de un reflejo deformado por convenciones genéricas, arquetipos e ideologías) de la situación de la mujer. Así, Susan Napier (1998) distingue en su artículo "Vampires, Psychic Girls, Flying Women and Sailor Scouts. Four faces of the young female in Japanese popular culture" cuatro arquetipos de la mujer joven procedentes del manga y el anime. Napier señala que ciertas imágenes de la mujer han servido, por un lado, para reforzar los roles tradicionales femeninos mientras que otras ofrecen una cierta evasión y relajación de las imposiciones del patriarcado. Ella estudia cuatro arquetipos femeninos concretos (la vampira, la chica con poderes psíquicos, la mujer voladora y la "Sailor Moon") en los que las jovencitas aparecen dotadas con un poder oculto que les concede cierta capacidad de acción sin perder en ningún momento su identidad femenina. En última instancia, Napier concluye que estos arquetipos femeninos japoneses tienen mayor relevancia en la cultura popular japonesa que en la occidental. En concreto, los arquetipos que ella explora ofrecen variadas combinaciones de feminidad y poder alternativas a la construcción de la mujer poderosa occidental (Napier, 1998: 105-106). 
Del mismo modo, Adams y Hill (1997), en su estudio sobre la mujer fálica en el cómic japonés, señalan que la mujer japonesa posee una posición secundaria en la sociedad salvo en el ámbito del hogar, donde se erige como principal autoridad y cuya influencia en el cuidado de los hijos determina el modo en que el niño concibe y se enfrenta a la figura de la mujer. En sus palabras, "Japanese mothers bind their children to them through physical closeness and seduction and utilize guilt to manipulate and control them. Boys experience this relationship to mother with profound ambivalence, falling in love for life with the maternal image, while expressing intense rage at females for the wrongs done to them under the guise of maternal love" (1997: 36). Así pues, estos autores concluyen que las imágenes de mujeres malvadas cargadas de atractivo, sexualidad y peligro, como en el caso de Tomie, son reflejos de la figura maternal puesto que la naturaleza sexual de la madre/mujer debe ser purificada y los complejos de impotencia masculina deben ser exorcizados (1997: 45).

Por otro lado, también existen aproximaciones que conciben al personaje femenino de ficción como entidad desligada de la realidad que, aunque tenga forma femenina, no pretende construir ningún significado o mensaje sobre la mujer real. Así, Vincent matiza las aproximaciones de Napier señalando que al estudiar los personajes femeninos del cómic como un reflejo de la vida de las mujeres en la cultura que produce estas obras se pierde la potencialidad de esta figura como criatura ficcional. En sus palabras, "if she were simply a representation of a certain social reality or ideology (be it feminist, misogynist, or otherwise), we would expect to find her in all sorts of media, including not only anime and manga but also novels, films, and theater. But just as the "final female" is inherently tied to the horror genre or the femme fatale to noir, the beautiful fighting girl is most at home in the "drawn" worlds of anime and manga" (Vincent, 2011: x).

Así, se establece una vinculación concreta con el medio en el que se construye esta determinada visión de la feminidad y con la imagen dibujada, en tanto que permite modificar aspectos esenciales de la realidad física. Satô ha abordado esta línea de estudio al analizar el arquetipo de la joven luchadora hermosa que hemos detectado de forma tan prominente en el cómic para jóvenes adolescentes en términos psicológicos a partir de los conceptos de Lacan. Así, él considera este personaje femenino no como un reflejo del status o los deseos de las mujeres sino como un objeto de deseo autónomo que permite transcender la realidad en el espacio ficcional donde se mueve. Según señala, "the icon of the beautiful fighting girl is an extraordinary invention capable of encapsulating polymorphous perversity in a stable form" (2011: 158).

Si atendemos a los personajes femeninos analizados en este artículo desde una doble perspectiva que integre la reflexión sobre la sociedad donde han sido creados y, al mismo tiempo, como entidades puramente ficcionales, es posible afirmar que la mujer en el cómic japonés dirigido a un público masculino desvela básicamente información sobre la posición y los deseos codificados taxonómicamente según las fórmulas genéricas establecidas del hombre. Así, en el cómic de acción y aventuras para adolescentes masculinos, encontramos 
una materialización vicaria de las aspiraciones del joven japonés a salir del anonimato, a romper las reglas sociales, a desarrollar una individualidad extrema y a situarse por encima de la figura femenina, relegada a desempeñar roles secundarios y a satisfacer la libido sexual a través de su construcción icónica atractiva. Por su parte, en el cómic de terror, que podemos entender como una manifestación de los temores sociales en los que las normas y la tradición se subvierten a través de la figura de la mujer monstruosa, el personaje femenino ocupa un lugar más prominente en la trama y plantea una relación más profunda con el hombre, lo cual puede ser interpretado como una reacción ante la autoridad maternal, la ansiedad sexual o la progresiva expansión de la mujer en diversas facetas de la vida social japonesa, dejando atrás así su rol tradicional como madre y ama de casa.

La mujer en el cómic japonés se convierte en una entidad con múltiples niveles de significación (icónica, narrativa, sociocultural) que es reconstruida en función de la tipología textual de la obra en la que aparece. En este artículo hemos abordado su utilización en dos tipos de cómics dirigidos principalmente a audiencias masculinas pero queda pendiente su estudio en los demás géneros que componen la industria del cómic japonés, lo cual pretendemos desarrollar en sucesivas investigaciones.

\section{BibLIOGRAFÍA}

- Adams, Kenneth Alan y Hill, Lester (1997): “The Phallic Female in Japanese Group-Fantasies". En The Journal of Psychohistory, Vol. 25, $\mathrm{n}^{\circ} 1$ (Summer), pp. 2-31.

- Barthes, Roland (1966): "Introducción al análisis estructural de los relatos". En Silvia Niccolini (ed.): El análisis estructural, 1977. Buenos Aires: Centro Editor de América Latina, pp. 65-101.

- Berndt, Jaqueline (1995): El fenómeno manga. Barcelona: Ediciones Martínez Roca.

- Bouissou, Jean Marie (2006): “Japan's growing cultural power. The example of manga in France". En Jaqueline Berndt y Steffi Richter (eds.): Reading Manga: Local and global Perceptions of Japanese Comics. Leipzig: Leipziger Universitätverlag, pp.149-165.

- Brienza, Casey (2009): "Paratexts in Translation: Reinterpreting "Manga" for the United States". En The International Journal of the Book, Vol. 6, $\mathrm{n}^{\mathrm{o}} 2$, pp.13-20.

- Bryce, Mio y Davis, Jason (2010): “An Overview of Manga Genres”. En Johnson-Woods, T. (ed.): Manga. An Anthology of Global and Cultural Perspectives. Nueva York: Continuum, pp. 34-61.

- Casetti, Francesco y Di Chio, Federico (1990): Cómo analizar un film. Barcelona: Paidós.

- Creed, Barbara (1993): The Monstrous-Feminine: Film, Feminism, Psychoanalysis. Nueva York: Routledge.

- Drummond-Mathews, Angela (2010): "What Boys Will Be: A Study of Shônen Manga". En Johnson-Woods (ed.): Manga. An Anthology of Global and Cultural Perspectives. Nueva York: Continuum, pp. 62-76. 
La representación icónica y narrativa de la mujer en el cómic japonés masculino:

el shounen manga y el horror manga

- Eisner, Will (1990): El cómic y el arte secuencial. Teoría y práctica de la forma de arte más popular del mundo. Barcelona: Norma Editorial.

- Freeland, Cynthia (1996): "Feminist Frameworks for Horror Films". En Leo Braudy y Marshall Cohen (eds.): Film Theory and Criticism, Introductory Readings. Oxford: Oxford UniversityPress, pp. 743-763.

- Gallego Andrada, Elena y Gándara Martín, Jesús de la (2010): “<<Cosplay〉> y otras tribus urbanas. Un estudio sobre los usos y abusosdel atuendo y otras conductas peculiares en las nuevas generaciones japonesas, y su repercusión sobre la salud mental y los modelos de imitación occidentales". En Revista Psicologia, Vol. 14, [en línea] Disponible en: http://www.psiquiatria.com/revistas/index.php/psicologiacom/article/view/1094/1037/ [2/02/2011]

- Goldberg, Wendy (2010): “The Manga Phenomenon in America”. En Toni Johnson-Woods. (ed.): Manga. An Anthology of Global and Cultural Perspectives.Nueva York: Continuum, pp. 281-296.

- Gómez Aragón, Anjhara (2011): "Interpretaciones del "manga" y el "anime” japonés en nuestra sociedad. La performance en el cosplay”. En Elena Barlés Báguena y David Almazán (eds.): Japón y el mundo actual. Zaragoza: Asociación de Estudios Japoneses en España, pp. 1033-1050.

- Ito, Kinko (2008): "Manga in Japanese History". En Mark MacWilliams (ed.): Japanese Visual Culture. Explorations in the World of Manga and Anime. Nueva York: M. E. Sharpe, pp. 26-47.

- Kinsella, Sharon (2000): Adult manga. Culture and power in contemporary Japanese society. Surrey: Curzon.

- Kristeva, Julia (1982): Powers of horror. An essay on abjection. Columbia. Columbia University Press.

- López Rodríguez, Francisco Javier y Juan Antonio García Pacheco (2011): “Arquetipos iconográficos femeninos en el cómic y la animación japonesa para adolescentes masculinos". En Vázquez Bermúdez, I. (coord.): Investigación y género. Logros y retos. Sevilla: Universidad de Sevilla.

(2011): "Internet como herramienta de distribución de productos culturales: el fansub y las scanlations". En Trípodos, Extra 2011, Life without media, pp. 629-639.

- Madrid, Daniel y Martínez, Guillermo (2010): "La ola nipona: Consumo de cultura popular japonesa en España”. En Pedro San Ginés Aguilar (ed.): Cruce de miradas, relaciones $e$ intercambios. Granada: Universidad de Granada, pp. 49-61 [en línea] Disponible en: http://www.ugr.es/ feiap/ceiap3/ceiap/capitulos/capitulo03.pdf [18/1/2012].

- McLelland, Mark (2001): "Local meanings in global space: a case study of women's 'Boy love' web sites in Japanese and English". En MotsPluriels, $\mathrm{n}^{\circ}$ 19, [en línea] Disponible en: http://www.arts.uwa.edu.au/MotsPluriels/MP1901mcl.html [18/1/2012].

- McWilliams, Mark W. (2008): “Introduction”. En Mark W.McWilliams (ed.): Japanese Visual Culture. Explorations in the World of Manga and Anime.Nueva York, M. E. Sharpe, pp. 2-25.

- Moliné, Alfons (2002): El gran libro de los manga. Barcelona: Ediciones Glénat.

(2003): "El terror en el manga”. En Jorge David Fernández; Jesús Jiménez y Antonio Pineda (eds.): El terror en el cómic. Sevilla: Comunicación Social Ediciones y Publicaciones, pp. 238-244.

- Mulvey, Laura (1975): "Visual Pleasure and Narrative Cinema". En Screen, Vol.16, no 3, pp. 618 . 
- Muro, Miguel Ángel (2004): Análisis e interpretación del cómic. Ensayo de metodología semiótica. Logroño: Servicio de publicaciones de la Universidad de la Rioja.

- Nagaike, Kazumi y Yoshi Kaori (2011): "Becoming and Performing the Self and the Other: Fetishism, Fantasy, and Sexuality of Cosplay in Japanese Girls'/Women's Manga". En Asia Pacific World, Vol. 2, no 2, pp. 22-43.

- Napier, Susan (1998): "Vampires, Psychic Girls, Flying Women and Sailor Scouts: Four Faces of the Young Female in Japanese Popular Culture". En Dolores Martínez (ed.): The Worlds of Japanese Popular Culture. Nueva York: Cambridge University Press, pp. 91-109.

. (2007): From Impressionism to Anime. Japan as Fantasy and Fan Cult in the Mind of the West. Nueva York: Palgrave McMilan.

- Natsume, Fusanosuke (2001): "East Asia and Manga Culture: Examining Manga-Comic Culture in East". En Ricardo Abad (ed.): The Asian Face of Globalisation: Reconstructing Identities, Institutions, and Resources, pp. 95-114 [en línea] Disponible en: http://www.apifellowships.org/pdffiles/A.pdf [14/01/2011].

- Propp, Vladimir (1928) [2001]: Morfología del cuento. Madrid: Akal Ediciones.

- Ruh, Brian (2001): "The Function of Woman-Authored Manga in Japanese Society". En Anime Research, [en línea] Disponible en: http://www.animeresearch.com/Articles/WomenInManga [2/10/2011].

- Saitô Tamaki (2011): Beautiful Fighting Girl. Minnesota: Minnesota University Press

- Santiago, José Andrés (2010): Manga. Del cuadro flotante a la viñeta japonesa. Vigo: Universidad de Vigo.

- Shamoon, Deborah (2008): "Situating the shoujo in shoujo manga: Teenage Girls, Romance Comics, and Contemporary Japanese Culture". En Mark MacWilliams (ed.): Japanese Visual Culture. Explorations in the World of Manga and Anime. Nueva York: M. E. Sharpe, pp. 137-154.

- Shiokawa, Kanako (1999): "Cute But Deadly: Women and Violence in Japanese Comics". En John A. Lent (ed.): Themes and Issues in Asian Cartooning: Cute, Cheap, Mad and Sexy. Kentucky: Bowling Green State University Popular Press, pp. 93-125.

- Takahashi, Mizuki (2008): "Opening the closed world of shoujo manga". En Mark MacWilliams(ed.): Japanese Visual Culture. Explorations in the World of Manga and Anime. Nueva York: M. E. Sharpe, pp. 114-136.

- Thorn, Matthew (2004): "Girls And Women Getting Out Of Hand: The Pleasure And Politics Of Japan's Amateur Comics Community”. En William W. Kelly (ed.): Fanning the Flames: Fans and Consumer Culture in Contemporary Japan. Nueva York: University of New York Press, pp. 169186.

- Varillas, Rubén (2009): La arquitectura de las viñetas. Texto y discurso en el cómic. Sevilla: Viaje a Bizancio Ediciones.

- Vincent, Keith J. (2011): "Making it real: Fiction, desire and the queerness of the beautiful fighting girl”. En Saitô Tamaki (2011): Beautiful fighting Girl. Minnesota: Minnesota University Press, pp. IX-XXV.

- Withrow, Steven y Alexander Danner (2007): Character Design for Graphic Novels. Massachussets: Focal Press. 